\title{
Huellas de la escritura nüshu en un cuento mexicano ${ }^{1}$
}

DOI: $10.32870 /$ mycp.v13i38.342

Claudia Macías Rodríguez ${ }^{2}$

\section{Resumen}

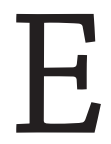

n este ensayo revisamos las huellas históricas de la escritura nüshu en el cuento El último signo, de Cristina Rivera Garza, considerando dos apartados principales. En primer término, las características históricoantropológicas del nüshu con base en estudios académicos sobre este lenguaje, y en segundo lugar el análisis del cuento desde una perspectiva hermenéutica que nos permita valorar las posibilidades de la ficción ante un hecho histórico.

Palabras clave: identidad, frontera, transmodernidad, Ricoeur, Dussel.

\section{Abstract}

This article analyzes the historical facts of the nüshu writing in the story $E l$ último signo, by Cristina Rivera Garza, considering two main sections. First, I interpret the historical and anthropologic characteristics of the nüshu from the academic studies about this language. Second, I do a hermeneutic interpretation about the text, in order to value the possibilities in the fiction-story against History.

Key words: identity, border, trans-modernity, Ricoeur, Dussel.

1. This work was supported by Research Fund Support Plan for Globalization Research by Foreign Professors Newly Appointed in 2008.

2. Universidad Nacional de Seúl. Correo electrónico: maciascl@snu.ac.kr 
Las mujeres dibujaban sus palabras en ropas y abanicos.

Las manos que los bordaban no eran libres.

Los signos, sí.

Contrabandistas de palabras ${ }^{3}$

\section{Introducción}

En 2004, los diarios del mundo se volcaron sobre una noticia por la novedad de su contenido para el público en general. Yang Huanyi, la última persona de China que sabía nüshu murió a los 98 años de edad, el 23 de septiembre, y con ella desaparecía este antiguo código de escritura utilizado exclusivamente por mujeres. ${ }^{4}$ El nüshu apareció hace siglos en la provincia de Hunan, al sur de China, como una respuesta a las condiciones sociales impuestas a las mujeres por el confucianismo. El diario español incluía en la nota unas palabras de la anciana: "Hizo nuestras vidas mejores porque nos ofreció un modo de poder expresarnos" (El Mundo). En la historia de la literatura universal la escritura femenina se abrió camino en un ámbito signado por estructuras jerárquicas patriarcales, por muros históricos y sociales que relegaban a las mujeres a un espacio restringido y predeterminado en épocas pasadas. En las letras hispanas recordemos a Gertrudis Gómez de Avellaneda, gran escritora cubana a quien nunca se le permitió el ingreso a la Real Academia Española, no obstante ser considerada una de las voces más auténticas del romanticismo hispano; aunque el ejemplo más reconocido se remontaría a la época colonial de México con Sor Juana Inés de la Cruz, quien englobaba "la creación femenina y masculina de su época", por lo cual se convertiría "en la voz poética de la Nueva España". ${ }^{5}$

3. Eduardo Galeano, "Contrabandistas de palabras", Espejos. Una historia casi universal. Siglo XXI Editores, Madrid, 2008, p. 32. Breve ensayo sobre la escritura nüshu.

4. China: "Last Inheritress of China's Female-specific Languages Dies", Xinhua News Agency, 23/9/2004; México: "Muere el nushu, idioma secreto de mujeres en China", El Universal, 23/9/2004; Chile: "La muerte de un lenguaje femenino", La Nación, 24/9/2004; Argentina: "Se extinguió el idioma que sólo hablaba el sexo femenino", Página 12, 26/9/2004; España: "Yang Huanyi, la única persona del mundo que hablaba 'nushu", El Mundo, 27/9/2004; Francia: "Ainsi meurent les langues", RFI, 28/9/2004; Italia: "Una lingua di donne per donne, unica nella storia, oggi minacciata di estinzione", Il Tempo, 4/10/2004; Portal UnEsco: Yang Huanyi, la última mujer china que dominaba la escritura nushu murió el 20 de septiembre de 2004, 6/10/2004.

5. Sara Poot Herrera, "El homenaje de 1991 a Sor Juana Inés de la Cruz", Y diversa de mí misma entre vuestras plumas ando, El Colegio de México, México, 1993, p. XV. 
Si consideramos la literatura - siguiendo a Barthes - no como un corpus de obras ni como categoría intelectual, sino simplemente como una práctica de escribir donde se realiza un trabajo de desplazamiento de la lengua, ${ }^{6}$ veremos que ha servido de vehículo de expresión de sentimientos y aconteceres de cuya suma deviene la identidad no sólo de los autores mismos sino la de todo un grupo social y cultural que no siempre encuentra sus límites en las fronteras de una nación, como es el caso de la generación de escritores mexicanos nacidos en los años sesenta. De dicha generación, Carlos Fuentes escogió a un grupo al que denominó "del boom al boomerang", Cristina Rivera Garza (Matamoros 1964) entre ellos. Escritora con gran prestigio en las letras mexicanas contemporáneas, ha sumado en su trayectoria literaria su profesión como historiadora y su innata inclinación por las letras. ${ }^{7}$

Cristina Rivera Garza ha mostrado especial interés por el movimiento cultural que se gesta actualmente en la frontera; prueba de ello es su exitoso Laboratorio Fronterizo de Escritores Writing lab on the border, realizado en 2006 con el apoyo del CNCA, de la Secretaría de Relaciones Exteriores, del Fondo de Cultura Económica, entre otras instituciones, con 19 autores menores de 35 años. Una reseña apuntó sobre esta labor: "La escritora insiste en que con este laboratorio busca mover la posición de la mirada del centro hacia las periferias, en un intento por redimensionar la producción cultural en México". ${ }^{8}$

Sin embargo, dicho interés va más allá de los límites geográficos, y en su último libro de cuentos, La frontera más distante (Tusquets, 2008), incluye un relato sobre el tema de la escritura nüshu bajo el título El último signo. Durante la presentación del libro en la FIL-Guadalajara 2008, Vanessa Vilches señaló que el libro "se escribe bajo la promesa y el desafío de la frontera. Los 11 cuentos nos sitúan en el abismo que supone toda línea divisoria”. Según afirmó la especialista en estudios de género, una frontera "es un lugar peligroso. Una frontera es sitiar el movimiento. Borde y centro a la vez, movimiento y

6. Roland Barthes, Lección inaugural (1977), Siglo xxi Editores, Madrid, 2007, pp. 120-124.

7. Doctora en Historia Latinoamericana por la Universidad de Houston, es una de las novelistas hispanoamericanas más destacadas del momento. Ha merecido en dos ocasiones el Premio Sor Juana de Novela (2001 y 2009), el Premio Anna Seghers (2005) en Alemania, el Premio Nacional de Novela José Rubén Romero (1997), entre otros. Cultiva además el relato corto y la poesía.

8. Sandra Licona, “Cruzan la frontera para analizar la realidad”, El Universal, Cultura, 23 de junio de 2006, p. 1. 
quietud". La postura de Rivera Garza, tanto en términos académicos como la que asume en los textos, nos permitiría ubicarla dentro del transcolonialismo propuesto por el filósofo Enrique Dussel, como portadora de una propuesta que busca traspasar las fronteras de temas y técnicas literarias de la modernidad, al tiempo que pretende romper los límites del centralismo, sumándose al proyecto "inacabado" de la descolonización. Dussel afirma: "las culturas china o vedantas no podrán nunca ser post-moderno-europeas, sino otra cosa muy distinta y a partir de sus propias raíces", ${ }^{9}$ y de aquí nuestro interés en revisar las huellas históricas de la escritura nüshu en el texto de Rivera Garza elegido como corpus de estudio, considerando dos apartados principales. Las características histórico-antropológicas del nüshu basándonos en los estudios académicos más reconocidos, seguidas del análisis del relato El último signo, desde una perspectiva hermenéutica, que nos permita valorar las posibilidades de la ficción ante un hecho histórico, a la luz de algunas premisas teóricas de Enrique Dussel (1934-) y de su maestro Paul Ricoeur (1913-2005).

\section{Nüshu, la escritura secreta de las mujeres}

El origen del nüshu aún no se ha podido precisar con exactitud. Algunos estudiosos lo consideran como el vestigio de una lengua antigua que dataría de la temprana dinastía Qin (221 a. C.- 207), mientras que otros - la mayoría- lo ven como un código especial de escritura creado por mujeres de una localidad del sur de China durante la dinastía Qing (1644-1911), derivado de los caracteres chinos tradicionales que en forma de diseños decorativos registraban dialectos locales. La publicación del informe de Zhebing Gong en 1983, pionero en la investigación del nüshu, atrajo la atención de la crítica tanto en China como en el extranjero y desde entonces se han publicado numerosos trabajos académicos sobre esa forma de escritura.

En la sociedad del sistema fengjian de China, ${ }^{10}$ las principales normas morales que una mujer debía seguir eran las "tres obediencias" del confucianismo:

9. Enrique Dussel, “Transmodernidad e interculturalidad (interpretación desde la filosofía de la liberación)", Filosofía y culturas, Pontificia Universidad Católica del Perú, Lima, 2005, p. 17.

10. Véase Bill Bruger y David Kelly, Chinese Marxism in the Post-Mao Era, Stanford University Press, Stanford, 1990, cap. 1, donde se expone el problema de la definición de las etapas del desarrollo en el proceso chino. En el estudio del desarrollo histórico de las sociedades asiáticas se incluye una redefinición de la historia china y de su pasado "feudal". Los autores consideran los argumentos de teóricos chinos como Wu Dakun que señalan la diferencia del sistema fen- 
obediencia al padre cuando era soltera, a su esposo después del matrimonio, y al hijo primogénito cuando quedaba viuda, además de las "cuatro virtudes" obligatorias: moralidad, discreción al hablar, modestia y diligencia. Estas reglas morales constituían una severa disciplina que oprimía a la mujer tanto física como mentalmente. ${ }^{11}$ Ante esa realidad, Liu Shouhua afirma que las descripciones de las heroínas y las aventuras de los textos en nüshu reflejan cierto tipo de liberación ante los refrenamientos de la moral confuciana. La imagen femenina que creaban era radiante, con una autosuficiencia y un vigor que concordaban plenamente con las inclinaciones de las mujeres trabajadoras, lo cual es bastante significativo. ${ }^{12}$ Además de las anteriores características, hay otras que reflejan la influencia de la psique femenina en la representación y la atmósfera de los grabados en nüshu. Por ello, McLaren afirma: "The enforced concubinage of women and their fierce resistance is the inspiration behind the central myth of the origin of nüshu". ${ }^{13}$

Los habitantes del distrito Jiangyong provenían de varios clanes. Algunos eran descendientes de pobladores del sur y otros de gente del norte. El empleo de la escritura nüshu era específico de Shangjiangxu y áreas adyacentes, una región montañosa al norte de Jiangyong en el extremo sur de la provincia de Hunan, sobre la frontera con Guangxi al sur de China. La población nativa comprendía una gama de grupos tribales no chinos, pero con el advenimiento de la colonización Han (la etnia china mayoritaria) a partir del siglo vi, la región asumió la cultura china aunque permaneció un sustrato de rasgos indígenas. Entre otros, estaban la práctica de la postergación del matrimonio, el que la novia no volviera a su pueblo natal hasta el nacimiento de su primer hijo, las relaciones entre muchachos y entre muchachas de la misma edad conocidas como hermandades juradas y cofradías, todo ello con una serie de manifestaciones que reflejaban la fuerza de los lazos fraternos. ${ }^{14}$ Varios investigadores coinciden en que las mujeres de estos grupos minoritarios tenían un estatus

gjian frente al feudalismo estilo europeo, resaltando aquellas particularidades constitutivas del Estado chino que lo colocan como referente del modo asiático.

11. Hak Siwon, "El nüshu de China y su sentido antropológico", Pueblo Nacional y su Cultura, núm. 9, 2000, pp. 5-11 [en coreano].

12. Liu Shouhua y Hu Xiaoshen, "Folk Narrative Literature in Chinese Nüshu: An Amazing New Discovery", Asian Folklore Studies, vol. 53, núm. 2, 1994, p. 314.

13. Anne McLaren, "Women's Voices and Textuality: Chastity and Abduction in Chinese Nüshu Writing”, Modern China, vol. 22, núm. 4, 1996, p. 399.

14. Anne McLaren, "Crossing Gender Boundaries in China: Nüshu Narratives", Intersections: Gender, History and Culture in the Asian Context, núm. 1, 1998, p. 2. 
social más alto y que eran más cultas, si bien señalan que esta peculiaridad no era única ya que se reconocen fenómenos similares en el delta del Cantón y en otros lugares, pero la invención de una escritura específica para transcribir dicha cultura sí es exclusiva de Shangjiangxu.

Los escritos en nüshu, literalmente "escritura de las mujeres", están considerados en su conjunto como una variante regional del género de la prosa lírica y popular de la cultura Han. La escritura nüshu se basa en el "tuhua Xiangnan", lengua de uso cotidiano en 10 distritos del sudeste de Hunan, incluyendo el de Jiangyong. El "tuhua Xiangnan" pertenece al grupo Han de la lengua china, aunque esto vaya en contra de la influencia de las lenguas minoritarias de las comunidades vecinas, según afirma McLaren citando a Zhao y Zhebing Gong (1990). Las mujeres de Shangjiangxu, privadas de recibir una educación formal, desarrollaron una escritura para poder comunicarse entre ellas, escritura que plasmaban en ocasiones en ropa o incluso en las palmas de las manos a manera de tatuajes.

Ahora bien, sólo una parte de esas mujeres podía escribir nüshu correctamente y conocía los registros necesarios para elaborar las "Cartas del tercer día" (san chao shu) y no todas tenían la facultad de poder enseñar a las generaciones más jóvenes los secretos de su escritura. ${ }^{15} \mathrm{Y}$ entre ellas, un número aún más reducido habrían sido capaces de interpretar o traducir los mensajes en nüshu, los cuales aparecían de vez en cuando con algunos caracteres chinos incluidos. Algunos especialistas señalan que los signos utilizados en esta escritura femenina corresponden a sólo una cuarta parte de los recursos lingüísticos del "tuhua Xiangnan". En términos de algunas de sus características lingüísticas particulares, tendríamos que

[...] in the nüshu system, words that sound the same in the local dialect can be written the same way, which is not true of ideographic official Chinese. In other words, while hanzi characters represent individual meanings, nüshu scripts can represent meanings as well as sounds. In addition, nüshu is written with rhomboid-shaped characters using oblique lines and arcs (unlike square hanzi). ${ }^{16}$

15. Liu Fei-Wen, "Righteousness, Romance and Transcendence: Gender, Class, and Genre in the Narratives of Liang Shanbo and Zhu Yingtai", International Workshop on Narration \& Genre, núm. 19-20 junio de 2008, p. 17.

16. Liu, Fei-Wen, "The Confrontation between Fidelity and Fertility: Nüshu, Nuge, and Peasant Women's Conceptions of Widowhood in Jiangyong County, Hunan Province, China", Journal of Asian Studies, vol. 60, núm. 4, 2001, p. 1052. 
Según afirma Cho, de un promedio de mil palabras básicas que poseía el nüshu, 700 se usaban con más frecuencia, además de que $80 \%$ de las letras consistía en modificaciones de los caracteres chinos ${ }^{17}$ y el $20 \%$ restante no se ha podido identificar todavía su origen:

Imagen 1

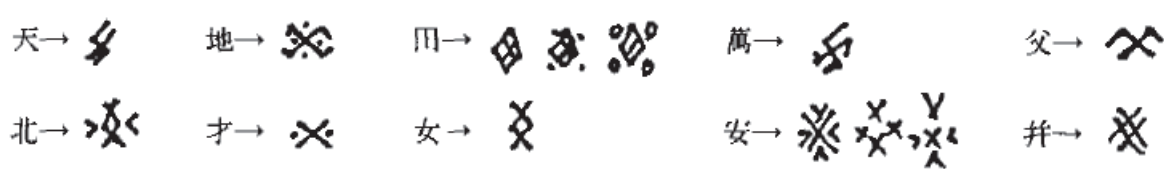

Yeomyeong Cho, 1995.

Por lo tanto, se trataría de un código lingüístico restrictivo basado en gran parte en fórmulas empleadas en la configuración de valores estereotipados, como afirma McLaren. ${ }^{18}$ La escritura nüshu contenía una serie de convenciones cuya función era expresar una forma de queja ritual con el fin de fortalecer los lazos de hermandad entre las mujeres. Por su parte, los hombres no sólo toleraron la cultura nüshu sino que hasta elogiaron el deseo de sus mujeres por utilizar la escritura, no obstante que estaban excluidos por completo de su conocimiento. Las especialistas en nüshu que fueron capaces de cultivar la fraternidad entre muchas hermanas juradas mediante el empleo del alfabeto nüshu, ganaron el reconocimiento de su pueblo y alcanzaron un alto rango en la sociedad. Si bien esta cultura de las mujeres surgió de y respondió a la ideología confuciana dominante del último periodo imperial, ofreció un dominio privado en el cual las mujeres pudieron inscribir fórmulas derivadas de su fantasía para dar consuelo y animar a la
La escritura nüshu contenía una serie de convenciones cuya función era expresar una forma de queja ritual con el fin de fortalecer los lazos de hermandad entre las mujeres

17. Cho Yeomyeong, "El nüshu y la cultura de China", Estudios sobre Mujeres de Asia, núm. 34, 1995, pp. 215 y 218 [en coreano]. La imagen con la traducción de algunas letras del chino al nüshu, mismo artículo, p. 221.

18. Anne McLaren, “Women's Voices...”, op. cit., p. 391. 
lucha por la autoafirmación, dentro de un restringido código lingüístico de su propia invención. ${ }^{19}$

En lo que se refiere a la relación con los sistemas de tradición oral de donde las mujeres tomaban muchas veces las historias para sus narraciones y canciones, el hecho de que la composición en verso fuera intrínseca a la producción del nüshu es de importancia central para nuestro estudio, por la carga literaria que conlleva. Las imágenes de subordinación de la mujer, de inferioridad e impotencia, más que insistir en la autocompasión aparecen como motivo para superar la adversidad, según coinciden la mayoría de los estudios más académicos, frente a la preferencia por el motivo de la opresión femenina difundida en la prensa y en varios espacios culturales en línea a la muerte de Yang Huanyi. Entre otros temas, por ejemplo se habla de sexo aunque se consideraba tabú, como ha demostrado el estudio de la historia de Liang-Zhu en nüshu:

Furthermore, talking about sex was almost a taboo in Jiangyong's daily linguistic practice, but sexual differences are bluntly discussed in this nüshu Liang-Zhu, such as Yingtai's "fragrant breasts" and her riddle of "the mouth of the ding". By singing or reading such narration, the pleasure of overstepping a "forbidden zone" was experienced. ${ }^{20}$

Por ello sería un error considerar que el nüshu fue únicamente un medio de expresión para las quejas individuales de las mujeres, ya que como afirma McLaren, el nüshu fue también un ejemplo de la mujer prototipo de conciencia de liberación. ${ }^{21} \mathrm{El}$ nüshu fue utilizado principalmente para la elaboración de las "Cartas del tercer día", folletos de paño en donde las mujeres transmitían a sus hijas consejos para el matrimonio. La escritura nüshu quedó plasmada especialmente en bordados. En columnas verticales de arriba hacia abajo y de derecha a izquierda, muchos de los caracteres están inspirados en los ideogramas chinos, como decíamos antes, si bien los del nüshu son más finos y estilizados, probablemente como producto del bordado, por lo cual se les llamó "mosquitos". ${ }^{22}$ Las cartas o misivas del tercer día contenían en las primeras páginas poesías con votos de felicidad, pero también mensajes con el dolor

19. Hak Siwon, op. cit., p. 7.

20. Liu Fei-Wen, "Righteousness...", op. cit., p. 28.

21. Anne McLaren, “Women's Voices...”, op. cit., p. 400.

22. Hak Siwon, op. cit., p. 5. 
de las madres, abuelas y tías por haber entregado a su hija, a la que se había ido y que tal vez no volverían a ver; más adelante había consejos y canciones escritas en este lenguaje que expresaban sentimientos y esperanzas, las cuales se enviaban tres días después de la boda, de ahí su nombre, y todo escrito en nüshu e ilegible para los hombres. ${ }^{23}$

Imagen 2

Bordado de Yang Huanyi

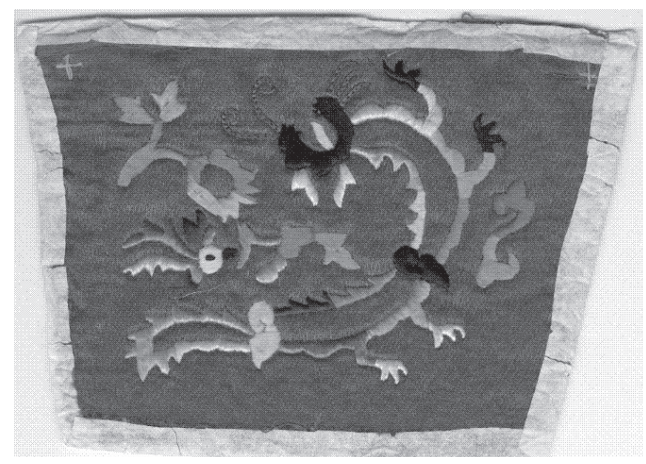

Colección Orie Endo (Japón).

Lingüistas y autoridades locales mostraron un especial interés por este lenguaje exclusivo de las mujeres y pusieron en marcha medidas para preservarlo. Cuando Zhebing Gong, profesor de la Universidad de Wuhan, descubrió el nüshu en 1982, había todavía una docena de ancianas familiarizadas con el lenguaje. Gao Yinxian, gran conocedora del nüshu, le confesó a Gong que había aprendido el código de su madre, ya que no se permitía a las mujeres ir a la escuela en su época. Todas las escritoras de nüshu fueron enterradas con sus trabajos, creyendo que podrían ayudarles en la siguiente vida, razón por la cual hoy permanecen muy pocos ejemplos de esta preciosa escritura femenina.

La rareza del lenguaje hace que la investigación sobre el origen del nüshu sea muy difícil, además de que desapareció prácticamente con el triunfo de la Revolución y el acceso de las mujeres a la educación formal.

23. Birgit Wegemann, "Cada palavra é uma flor. Nüshu, a escrita das mulheres", Cadernos de Tipografia, Lisboa, núm. 9, 2008, p. 22. 
Yang Huanyi (1909-2004)

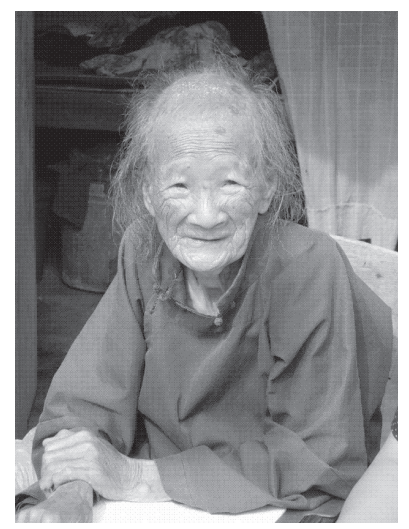

Foto: Timothy O’Rourke, Symposium 2000.

Por fortuna la Universidad de Qinghua, una de las más importantes de China, entró en contacto con Yang Huanyi unos años antes de su muerte y logró que escribiera una serie de poemas y canciones en nüshu que actualmente están siendo estudiados por lingüistas de todo el mundo. Después de muchos esfuerzos, se ha publicado un libro con textos en nüshu gracias al cual en universidades chinas y de otros países existe hoy en día una comprensión considerable, contando ya con buen número de textos académicos sobre el estudio de esta lengua. El 23 de septiembre de 2004, la muerte de Yang Huanyi significó la extinción del nüshu, ya que hoy en día las chinas reciben la misma educación que sus compatriotas varones, las condiciones sociales han cambiado y el valor original del nüshu se ha perdido por completo.

No obstante, quedan una serie de textos en los que "cada palabra es como una flor", según han descrito los caracteres algunos expertos, único testimonio de que un día existió un lenguaje que fue propiedad exclusiva de las mujeres. Actualmente, en cooperación con la administración local de Hunan, el Centro de Investigación de la Cultura Nüshu tiene en marcha un proyecto para rescatarlo. El proyecto incluyó una biblioteca de referencia para estudios sobre nüshu, un museo, un pueblo cultural y un simposio internacional que se ha seguido celebrando anualmente. Cerraremos este apartado con un poema de Cizhu en nüshu traducido al inglés, una mujer campesina nacida a principios del siglo xx en una pequeña población en Jiangyong, provincia de Hunan, cantando su dolor por la pérdida de su esposo: 
When I was young, I counted on my husband.

When I turn old, I will rely on my son.

If I have neither husband nor son, whom should I depend upon? ${ }^{24}$

\section{Presencia del nüshu en El último signo}

Hayden White señala que cuando los teóricos de la literatura han estudiado la estructura de las narraciones históricas, por lo general han sido reticentes a considerarlas como lo que manifiestamente son: "ficciones verbales cuyos contenidos son tanto inventados como encontrados y cuyas formas tienen más en común con sus homólogas en la literatura que con las de las ciencias". ${ }^{25}$ Huellas y cronología. Recursos de la historia en la tarea y ante el problema de representar el tiempo son objeto de estudio en la obra de Paul Ricoeur Tiempo y narración, en donde se afirma que el tiempo propiamente histórico media entre el tiempo vivido y el tiempo cósmico. ${ }^{26} \mathrm{Y}$ para demostrar su tesis, el filósofo francés acude a lo que llama "procedimientos de conexión" que garantizan la "reinscripción del tiempo vivido en el tiempo cósmico: calendarios, sucesión de generaciones, archivos, documentos, huellas". ${ }^{27}$

En El último signo, Cristina Rivera Garza presenta la historia de una mujer china que desaparece arrebatada por un remolino en plena ciudad el mismo día en que muere Yang Huanyi; ambas habrían sido las últimas mujeres que conocían la escritura nüshu. Una detective investiga el caso denunciado ante la policía por el hombre que acompañaba a la mujer al momento de la desaparición. Y en el desarrollo de la fábula, las huellas de la historia son evidentes, como lo mostraremos después. Nuestro corpus de estudio es un texto de ficción con un sustrato histórico que se fue reforzando a medida que aparecieron las sucesivas ediciones y sus varias publicaciones. La historia de El último signo se cierra en 2009, cuando Rivera Garza graba la lectura del cuento en el sitio Descarga cultura. UNAM:

24. Liu Fei-Wen, "The Confrontation...", op. cit., p. 1051.

25. Hayden White, "El texto histórico como artefacto literario" (1978), El texto histórico como artefacto literario y otros escritos, Paidós, Barcelona, 2003, p. 109. Cursivas del autor.

26. Paul Ricoeur dialoga con la obra de Hayden White en lo que se refiere a la naturaleza esencialmente "prefigurativa" que propone el segundo, en términos de la función de los tropos en el discurso histórico. Véase Paul Ricoeur, Tiempo y narración III. El tiempo narrado (1985), Siglo xxi Editores, México, 1996, pp. 855-863.

27. Ibíd., p. 777. Cursivas del autor. 
Hola, soy Cristina Rivera Garza. Voy a leerles un cuento cuyo título es El último signo; es uno de los cuentos que forman parte del libro La frontera más distante que publiqué el año pasado, en 2008. El cuento tiene su punto de origen en una noticia muy extraña que leí en el periódico; se trataba sobre el fin de una lengua, de la lengua nüshu; me intrigó mucho el hecho de que una lengua pueda desaparecer, de que la última hablante de nüshu acababa de morir. Y basada en este tipo de vacío que la falta de un lenguaje abre en el mundo, empecé a escribir este cuento. Ya después entraron muchas otras cosas. ${ }^{28}$

La escritora señala como primera fuente la noticia que pudo haber leído en 2004, año de la muerte de Yang Huanyi, a la que se sumaría luego la experiencia del viaje a China en junio de $2006 .{ }^{29}$ Rivera Garza viaja por razones académicas a Xi'an, llamada Chang'an en la Antigüedad, famosa por los Guerreros de Terracota de la tumba del emperador Qin Shi Huang, que aparecerán en el cuento. Sin embargo, el nombre moderno de dicha ciudad es homófono de Xian, denominación con que se conoce a la provincia de Hunan, cuna del nüshu, por el río Xian que la atraviesa. La protagonista del cuento también se llama Xian. El 5 de julio del mismo 2006, la escritora envía el archivo de El último signo para la antología de jóvenes escritores hispanoamericanos que se preparaba en la Universidad Nacional de Seúl, ${ }^{30}$ señalando que se trataba de "un cuento reciente"; la traducción al coreano comenzó al tiempo que se publicaba el cuento en español en el segundo número de Cuaderno Salmón. Creación y Crítica (octubre de 2006), en la sección "La imaginación" ${ }^{31}$ En ambas ediciones el cuento incluye el siguiente epígrafe: "El ejecutor de una empresa atroz debe imaginar que ya la ha cumplido, debe imponerse un porvenir que sea irrevocable como el pasado. Jorge Luis Borges, El jardín de los senderos que se bifurcan".

Rivera Garza entrega dos años después de la muerte de Huanyi un texto que pareciera el laboratorio de donde hubiera nacido su famosa novela $\mathrm{La}$

28. "En voz de Cristina Rivera Garza [El último signo]", Letras mexicanas en la voz de sus autores, UNAM, México, 2009, en: http://www.descargacultura.unam.mx/app1\#up. La transcripción es mía.

29. Durante su viaje a China, la Universidad Nacional de Seúl la invitó a presidir el Coloquio Últimas tendencias de la literatura mexicana. Invitada especial: Cristina Rivera Garza, Instituto de Estudios Iberoamericanos, Universidad Nacional de Seúl, 5 de junio de 2006.

30. Cristina Rivera Garza, "El último signo", en Claudia Macías (ed.), Sube a la alcoba por la ventana, Munhak Dongnae, Seúl, 2008, pp. 163-194 [en coreano].

31. Cuaderno Salmón apareció en ocho números de 2006 a 2008, con el apoyo de la Coordinación de Difusión Cultural unAM. Agradecemos la información proporcionada por David Miklos, creador y editor de la revista, sobre detalles de la publicación del cuento en dicha revista. 
cresta de Ilión (2002), con un mundo creado por mujeres y también exclusivo por el lenguaje ininteligible para los hombres. El epígrafe es, ciertamente y como lo reconoce la autora, ${ }^{32}$ una guía de entrada para la lectura gracias a los puntos en común con el cuento de Borges: el género negro, ya que se trata de un cuento de detectives, el personaje chino, el signo que motiva toda la trama, la estructura como laberinto con mundos ajenos entre sí debido al manejo del tiempo y el cuestionamiento de la identidad y de la realidad que nos circunda frente al mundo del pensamiento. Pero la autora decidió eliminar dicho epígrafe en la edición final, de manera que la versión incluida en La frontera más distante no tiene enunciado alguno, y sí, en cambio, se agrega un elemento de suma importancia: una muestra de escritura nüshu con su traducción al chino, procedente de la colección estudiada y publicada por Orie Endo, ${ }^{33}$ especialista japonesa en nüshu:

\section{El último signo}

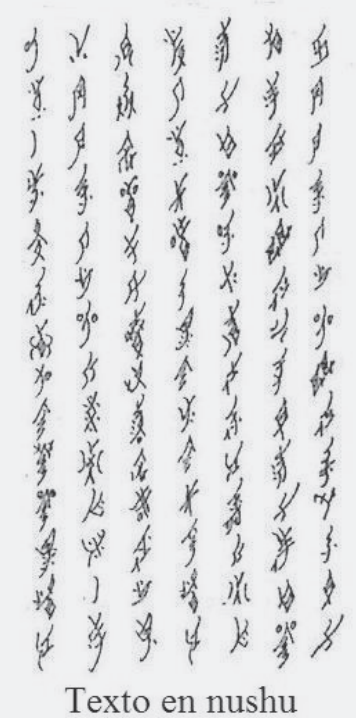

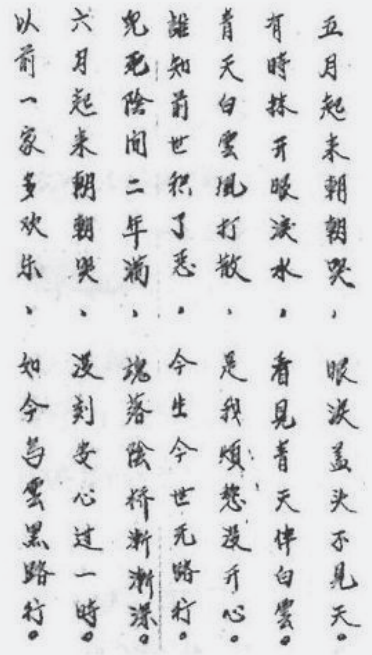

Texto en chino

Tusquets, 2008, p. 201, Colección Orie Endo (Japón).

32. Agradecemos a Cristina Rivera Garza por orientarnos en algunas dudas surgidas durante la elaboración del presente trabajo.

33. Association of Asian Studies Orie Endo, Bunkyo University, Japón. 
Ricoeur se cuestiona sobre el significado de decir que algo ha sucedido "realmente", para referirse luego al papel que desempeña el carácter selectivo de la búsqueda, de la conservación y de la consulta de los documentos, y es precisamente en el manejo de dichos documentos donde se marca la línea divisoria entre historia y ficción: "A diferencia de la novela, las construcciones del historiador tienden a ser reconstrucciones del pasado. A través del documento y por medio de la prueba documental, el historiador está sometido a lo que, un día, fue" ${ }^{34}$ La ficción, en cambio, está en libertad de escribir las posibilidades no efectuadas del pasado histórico, lo que pudo haber sucedido, además de que tiene el poder de explorar otra frontera, la de los confines entre la fábula y el mito. Ricoeur define la tarea del historiador frente a la del escritor de ficción, señalando que a diferencia del novelista, el historiador tiene una doble misión: a) construir una imagen coherente, portadora de un sentido único, y b) construir una imagen de las cosas, tal como fueron en realidad y de los acontecimientos, tal como sucedieron realmente. El historiador debe localizar todas las narraciones históricas en el mismo espacio y en el mismo tiempo; debe poder vincular todos los relatos históricos en un único mundo. ${ }^{35}$ En contraparte, tenemos que en la ficción existe la posibilidad de ofrecer más de un sentido y de construir imágenes en distintos espacios y tiempos.

Las huellas históricas que podemos encontrar en El último signo coinciden casi en su totalidad con el referente de donde provienen. El cuento incluye desde las primeras páginas la noticia de la muerte de Yang Huanyi en el distrito de Jianyong de la provincia de Hunan:

— ¿Sabía —le preguntaría la Detective ocultando los ojos en la taza de caféque ese día murió en la provincia de Hunan alguien relacionado con su amiga? — ¿Yan [sic] Huanyi? — preguntaría él a su vez, incrédulo.

-Así es -mencionaría, extendiéndole un papel muy delgado y de color amarillento que parecía, y esto también le pareció increíble, un telegrama. ${ }^{36}$

El dato histórico se incluye con toda precisión. Se trata de la misma mujer china que se consideró como la última heredera de la escritura nüshu; el nombre - el leve cambio no alcanza a ser significativo-y el lugar no dejan

34. Paul Ricoeur, 1996, p. 837. Cursivas del autor.

35. Cf. Ibíd., p. 844.

36. Cristina Rivera Garza, "El último signo", La frontera más distante, Tusquets, México, 2008, p. 198. Cito por esta edición. 
lugar a dudas. En seguida, el narrador, ubicado desde una posición externa a los hechos, al igual que un historiador, incluye una amplia reseña del conocimiento que el protagonista tenía sobre la escritura nüshu:

El Hombre que Temía a los Remolinos sabría que el nushu es una lengua secreta. Era. Sabría que las mujeres de la provincia de Hunan lo habían creado en el siglo III y que, desde entonces, lo transmitían de generación en generación como un escandaloso secreto femenino. Sabría todo lo que le había dicho Xian de esa escritura de mujeres: que era una forma de expresión en un medio de otra manera opresivamente masculino; que se inscribía en papel o se pintaba sobre abanicos o se bordaba en pañuelos; que componía las asíllamadas Misivas del Tercer Día con que las amigas y familiares le mandaban consejos a la recién desposada. A la mujer ida. Sabría que el nushu constaba de rasgos delgados y finos — rasgos que a él le parecían encantadores-. Y sabría, por supuesto, del abismo entre la provincia de Hunan y los soldados de terracota de Xian y, por eso, no le habría creído nada. Por eso la habría dejado hablar (pp. 200-201, subrayado mío).

Inmediatamente después de la cita anterior, la autora incluye la imagen de un texto en nüshu con su traducción al chino, modificando sustancialmente para el lector el sentido de la penúltima frase de la cita. El hombre no le ha creído nada a Xian y en la primera versión del cuento la incredulidad quedaba a discreción del lector, que podría estar o no de acuerdo con la percepción del personaje. Pero la inclusión del texto en nüshu en la edición última anula y desmiente la negación del hombre: la muestra deja de manifiesto la existencia de dicha escritura exclusiva de las mujeres, ya que el fragmento en nüshu aparece prácticamente idéntico al original. Asimismo, llama la atención en la cita anterior el detalle de la precisión geográfica aludiendo a la distancia real que existe entre Xi'an, con sus Guerreros de Terracota, y Xian (provincia de Hunan).

Páginas adelante, una vez que la desaparición de Xian ha motivado una investigación policiaca, la Detective a cargo del caso recibirá el informe de su ayudante:

El Policía Joven le diría, como el penúltimo punto del reporte del día, que según sus someras investigaciones el nushu, efectivamente, había existido y, efectivamente también, había desaparecido. Se trataba de una especie de código secreto producido por mujeres de la provincia de Hunan que, desde el siglo III, se transmitía de generación en generación. Le mostraría entonces una hoja donde se comparaban los caracteres nushu y los caracteres chinos y, con ella entre las manos, la Detective 
podría constatar que los primeros eran cuadrados, y los segundos cursivos y delgados (p. 212, subrayado mío).

El carácter oficial del anterior intertexto — reporte de policía- le confiere un rango de verdad histórica y se ofrece al lector como un dato confiable dentro de la ficción, sumado al hecho de que el cuento en su versión definitiva efectivamente incluye una muestra real de escritura nüshu con su correspondiente traducción al chino. Con todo ello, de nuevo la credibilidad en el hombre queda disminuida. Como pruebas tenemos esa hoja con la escritura nüshu y el diario que encuentra la Detective y que conserva de manera subrepticia:

Esa información la colegiría ella, días después, de su lectura del diario de tapas forradas con satín rojo-anaranjado que reposaba, contra las reglas de su oficio, dentro del cajón de su escritorio. No sólo era que el cuaderno contenía una suerte de escritura en dos letras distintas que la intrigaba, sino que también el objeto le parecía hermoso (p. 203).

El diario en cuestión sería la recopilación de las Cartas del Tercer Día que se entregaban a las recién casadas a manera de álbum, en donde podían seguir añadiendo las misivas que intercambiaban con otras mujeres de la fraternidad. Sin embargo, el cuento propone un nuevo sentido. La Detective supone que las dos escrituras que encuentra en el diario corresponden a un hombre y a una mujer, con lo cual se rompería la hipótesis de la escritura exclusiva de las mujeres. Al final del cuento descubriremos que la doble escritura respondía a los nuevos sentidos que iba adquiriendo el texto impreso conforme avanzaba la relación entre Xian y el hombre, y a la inclusión de la escritura de un tercero, el "otro" necesario para la definición del "yo", en este caso, de Xian.

En El último signo nos encontramos ante un cuento en donde sólo dos personajes tienen nombre: Xian, la mujer china que desaparece arrebatada por un remolino, y Yang Huanyi, personaje que tiene como referente a la última mujer que conocía el lenguaje nüshu en la región de Hunan — también llamada Xian - en China. ${ }^{37}$ El resto de los nombres, siempre con mayúscula en

37. Cabe destacar que el nombre de Xian ya estaba presente en la escritura de Rivera Garza desde el año 2000. Dos cuentos publicados en una antología local de Nuevo León tienen un personaje con este nombre. En Carta para la desaparición de Xian, el narrador habla de Xian que se ha ido para siempre, y en El desconocimiento, Xian es el nombre falso de una de las protagonistas. Cuentistas tamaulipecos. Del fin de siglo, al nuevo milenio, Orlando Ortiz (ed.), Instituto Tamau- 
el texto, se da a los personajes por sus acciones: la Detective, el Joven Policía. Pero sin duda el caso más interesante es el del protagonista, el Hombre del Árbol, primera denominación que alude el haberse sujetado de un árbol en el momento de la desaparición de Xian.

La personalidad masculina aparece con mayor ambigüedad en un mundo donde el secreto pertenece a las mujeres. El lector va descubriendo la inseguridad de su personalidad mediante el sucesivo cambio de nombres y la variación de los tiempos verbales, que terminan por mostrarnos al final el enigma que se cifra sobre su destino. Rivera Garza afirma:

Si los nombres en sí mismos tienen una carga cultural enorme y las identidades fluyen y son relacionables, por qué no designar a estos personajes por lo que sus acciones y sus prácticas dictan en momentos distintos. Un hombre del desierto puede ser en otro momento un hombre mudo; lo que lo define es su práctica y no algo anterior elegido por otros y que trata de fijarlo. ${ }^{38}$

Si bien la Detective también recibe otras denominaciones - Mujer Tensa, Mujer a Punto de Romperse-, son mínimos los cambios en la caracterización del personaje en comparación con el hombre que experimenta 10 nombres a lo largo del relato:

- $\quad$ El Hombre del Árbol (195).

- El Hombre Frente a la Puerta (200).

- El Hombre que Temía a los Remolinos (200).

- El Hombre Abrazado a un Árbol (202).

- El Hombre que Temía a los Remolinos (203).

- El Hombre que Juraba Haber Perdido una Mujer China (206).

- El Hombre que Tenía Frente a Sí (207).

- El Hombre Sin Respuestas (207).

- El Hombre que Juraba Haber Perdido una Mujer China (208).

- El Hombre Tatuado (211).

- El Hombre que Temía a los Remolinos (213).

lipeco para la Cultura y las Artes, Ciudad Victoria, 2000, pp. 397-401 y 387-396, respectivamente.

38. Jorge Luis Herrera, "El amor es una reflexión, un volver atrás. Entrevista con Cristina Rivera Garza”, El Universo del Búho, núm. 60, 2005, p. 50. 
- El Hombre Que Juraba Haber Perdido a una Mujer de la China (214, subrayado mío).

- El Hombre Que Juraría Haber Perdido una Mujer de la China (217, subrayado mío).

Las dos últimas denominaciones son dignas de consideración especial. La mayúscula del pronombre relativo "que" (p. 214), a diferencia de seis páginas antes, manifiesta con más fuerza el deseo del hombre de que le crean lo que dice. En cambio, líneas antes de concluir el cuento el lector descubre que el hombre mismo no está seguro de que haya sido cierta la desaparición de la mujer y, lo más importante, el narrador tampoco le cree. La voz narradora elige el tiempo pospretérito "juraría", que significa una probabilidad en el pasado, con lo cual queda anulada por completo. El texto habla de "esa oscuridad respecto al sujeto" (p. 210), que en un primer momento se podría haber pensado acerca de Xian, pero que la Detective descubre que se refiere al hombre.

El hombre que amó a Xian comienza con la certeza de haber descubierto el placer del amor a su lado. Xian, como las mujeres poseedoras del secreto del nüshu, recrea una narración en donde mezcla una historia de amor con la poesía del encuentro erótico para transmitirla a su hermana jurada, en este caso reencarnada en la Detective:

Sólo así se podía explicar, le diría al Policía Joven un poco más tarde ese mismo día, la autoría itinerante de cada entrada del diario. Ese no saber. Esa oscuridad respecto al sujeto. Sólo así podía explicarse que el diario, que la escritura del diario, constituyera, a la vez, la revelación más íntima y el enmascaramiento perfecto de los dos (p. 210).

Xian deja su último testimonio en el cuerpo mismo del hombre. El tatuaje que se descubre detrás de su oreja y que inicialmente la Detective interpretara como un trébol, resulta ser un signo en nüshu, el último signo de la escritura secreta de las mujeres inscrito, grabado en la piel del hombre, que ha quedado reducido a sí mismo, sin personalidad ni autoridad alguna frente a la sociedad que pierde la confianza en su palabra:

Recordaría que habían hablado de eso, del tatuaje. Del último vocablo. De la marca que llegaría a representar, en el futuro, en un futuro inimaginable, la palabra fin. El hecho. 
-El fin de la escritura - le había susurrado entonces, su mano derecha sobre el pezón rosado de la mujer, los labios olorosos a jazmín sobre su cuello (p. 213).

En los textos de la escritura nüshu los especialistas han encontrado como constante el sometimiento al hombre — al menos en la primera etapa del matrimonio-y la casi divinización que hacen de la figura masculina, conceptos acordes con el pensamiento confucianista vigente en la sociedad de la época:

The women said, "How exceedingly great is the husband!"

Lady Ban responded, "The husband is heaven. Can one not be devoted to him? In antiquity, when a woman went to be married, she was said to be going home. She transfers her heaven to serve her husband. The principle in this is vast. It is the pattern of heaven, the standard of the earth, the norm of conduct for the people. ${ }^{39}$

En el texto de Rivera Garza se ha traspasado la frontera. Xian ha roto la barrera y, de su condición como mujer dominada, cambia su papel actancial asumiendo el poder de dominar que antaño residiera exclusivamente en los hombres.

\section{Conclusión}

La ficción tiene la posibilidad de ofrecer más de un sentido y de construir imágenes en distintos espacios y tiempos, creando cronotopos cero acordes con la época de globalización de la cultura y del cuestionamiento de las fronteras en relación con los centros culturales hegemónicos. Grimson sostiene que la categoría de "frontera" constituye un concepto complejo que sigue siendo difuso a partir de su duplicidad, debido a que frontera fue y es simultáneamente un objeto-concepto y un concepto-metáfora, ya que de una parte parece haber fronteras físicas, territoriales y, de la otra, fronteras culturales, simbólicas. ${ }^{40}$ Rivera Garza diluye en su texto las fronteras entre la fantasía, la realidad, el sueño, la vigilia, el tiempo, el silencio, la memoria, la locura y

39. Susan Mann y Cheng Yu-Yin, "The Book of Filial Piety for Women. Attributed to a Woman Née Zheng (ca. 730)", Under Confucian Eyes. Writings on Gender in Chinese History, Universidad de California, Berkeley, p. 53.

40. Alejandro Grimson (ed.), Fronteras, naciones, identidades. La periferia como centro, Cicus, Buenos Aires, 2000, p. 9. 
todo lo que se resista a ser contado ${ }^{41} \mathrm{y}$, en esta misma dirección, la escritora agrega en otra entrevista:

Nos interesa reconocer la existencia de distintas y plurales tradiciones de pensamiento, de escritura, de ahí la variedad de los invitados. Lo que estamos haciendo es invitar a la reflexión y a la práctica de distintos tipos de escrituras, especialmente aquellas que cruzan fronteras de géneros literarios, o que se proponen exploraciones en el lenguaje. ${ }^{42}$

En El último signo nos encontramos con una ficción verbal "cuyos contenidos son tanto inventados como encontrados", como decíamos al inicio citando al filósofo e historiador Hyden White, quien declaró sobre este particular al término de una entrevista: "Finalmente no creo que podamos describir la realidad o comprometernos con ella sin utilizar un lenguaje figurativo. Eso es todo". ${ }^{43}$ Cristina Rivera Garza, como historiadora también, profundiza en el fenómeno de la escritura nüshu para plasmar su fuerza simbólica en el contexto actual de la narrativa urbana, en términos del problema de la identidad. Los componentes históricos, junto con los propiamente ficticios, se integran en términos de una propuesta simbólica que, no obstante sus claras referencias históricas, se encuentra en estrecha relación con la salida mítica del final del cuento. El remolino, según la tradición oral popular, trae en su centro la presencia del demonio:

El concepto del diablo simboliza miedos, aberraciones y anomalías, la rebeldía y disturbios del orden, trasgresiones de los límites [...] el diablo como principio de lo otro, abarca todo aquello que no podemos comprender [...] La historia cultural demuestra que eran juzgados como diabólicos desde simples deseos de ser diferente, obsesiones, la voluntad a la contradicción y oposición hasta incluso el afán por la libertad. ${ }^{44}$

41. Jorge Luis Herrera, op. cit., p. 48.

42. Sandra Licona, op. cit., p. 1. Cabe señalar la participación de Cristina Rivera Garza en el libro Un hombre a la medida (Cal y Arena, 2005), en el cual junto con otras escritoras mexicanas de su generación escriben (re/de)construyendo el cuerpo de un hombre.

43. Alfonso Mendiola, "Hayden White: la lógica figurativa en el discurso histórico moderno. Entrevista a Hayden White", Historia y Grafía, enero-junio 1999, en: http://www.hemerodigital. unam.mx/anuies

44. Isabella Leibrandt, "La figura del diablo en las tradiciones populares germánicas y occidentales”, Culturas Populares. Revista Electrónica, núm. 4, enero-junio 2007, en: http://www.culturaspopulares.org/textos4/articulos/leibrandt.htm 
En El último signo los personajes femeninos, únicos que poseen un nombre definido, están caracterizados como entidades autónomas dueñas de su discurso y, por lo tanto, de su propia historia personal, en contraparte con los masculinos, que se quedan al margen de la definición nominal y que terminan dudando de su propia memoria histórica.

Dussel cuestiona la hegemonía central e ilustrada de Europa, que no tiene sino dos siglos de existencia, 1789-1989:

¡Sólo dos siglos! Demasiado corto plazo para poder transformar en profundidad el "núcleo ético-mítico" (para expresarnos como Ricoeur) de culturas universales y milenarias como la china y otras del extremo Oriente (como la japonesa, coreana, vietnamita, etc.), la indostánica, la islámica, la bizantino-rusa, y aun la bantú o la latinoamericana (de diferente composición e integración estructural). Esas culturas han sido en parte colonizadas [...] pero en la mejor estructura de sus valores han sido más excluidas, despreciadas, negadas, ignoradas más que aniquiladas. $^{45}$

Configurar el pasado narrativamente es algo inherente a nuestra comprensión del mismo como pasado humano. La extensa obra de Ricoeur, Tiempo y narración, encamina su conclusión hacia una identidad narrativa o narrada, ya que la pregunta por la naturaleza del ser del yo, según afirma el filósofo, se contesta narrando una historia, contando una vida: "Podemos saber, en efecto, lo que es el hombre atendiendo la secuencia narrativa de su vida". ${ }^{46}$ Rivera Garza traslada en El último signo la tradición de una escritura que liberó a las mujeres del silencio que les imponían las estructuras sociales, a un espacio donde la víctima ${ }^{47}$ es un hombre que duda no sólo de su memoria sino de su propia identidad como existencia. niv

45. Enrique Dussel, op. cit., p. 17.

46. Paul Ricoeur, Tiempo y narración I. Configuración del tiempo en el relato histórico (1983), Siglo xxi Editores, México, 1995, p. 12.

47. 'El concepto de 'trans-modernidad' supone también la categoría de víctima, de exterioridad (la exclusión cultural de las víctimas de la Modernidad)” (Enrique Dussel, op. cit., p. 28). 